S. Zh. GALIEV ${ }^{1}$, Head of Department, Professor, Doctor of Engineering Sciences, seitgaligaliyev@mail.ru

E. T. UTESHOV ${ }^{2}$, Head of Laboratory, Doctoral Student

D. A. GALIEV ${ }^{2}$, Head of Laboratory, Candidate of Engineering Sciences

K. A. FARAKHOV ${ }^{3}$, Engineer

${ }^{1}$ Kunaev Institute of Mining, Almaty, Kazakhstan

2 Institute of Geology, Satbaev University, Almaty, Kazakhstan

${ }^{3}$ Mining Technology Science Center, Nur-Sultan, Kazakhstan

\title{
METHODS AND TECHNIQUES FOR ENERGY EFFICIENCY ASSESSMENT OF GEOTECHNOLOGICAL FACILITIES AT OPENCAST MINES BASED ON THE IN-DEPTH ANALYSIS
}

\begin{abstract}
Introduction
The energy intensity of the main technological processes in solid mineral mining using the opencast method and cyclical technologies takes up to $60-70 \%$ of the total cost of production and haulage operations. With the given mining technologies, when the directions and procedures for stripping and excavation are determined, the main routes of searching for the potential to reduce the process energy intensity are associated with the appropriate choice of models of the main mining and haulage equipment, its duty and operation conditions [1-5]. As the analysis of the mining practices in Kazakhstan and in many other countries of the world shows, the management of the energy consumption process focuses on energy saving. At the same time, the energy saving efforts often fail to increase in efficiency or to decrease the mining and haulage cost. This situation is explained, first of all, by the lack of a developed energy efficiency methodology, including a number of disimprove effective solutions. This article reveals the possibilities and a potential for real energy efficiency improvement in opencast mines.
\end{abstract}

\section{Methodology}

One of the essential factors of the energy efficiency increase at geotechnological facilities in opencast mining is the in-depth analysis. This process should ensure monitoring and assessment of energy consumption per operation, governed, in turn, by the mode and operating conditions of the main mining and haulage equipment. The general information chart of the energy consumption/efficiency assessment is shown in Fig. 1. Implementation of this approach requires appropriate methods and techniques that allow adequate accounting of the main factors affecting performance of mining and haulage machines. In this case, energy efficiency is assessed based on the adequate accounting for operationby-operation energy consumption and the nature of integration of these energy inputs into the forming energy flows of the technological process as a whole.

Energy efficiency involves not only simple reduction in energy consumption, but first of all is considered in conjunction with the overall efficiency of the geotechnological facilities, which is assessed using a set of technical and economic criteria. In this regard, it is fundamentally important in analyzing and assessing the energy efficiency of the investigated technological processes to be based on the adequate accounting of all main operational costs of the mining process. For these purposes, the methodology of process management economics is applied.

All above factors are inherent in the process approach in the management of complex and large-scale systems, to which geotechnological facilities in opencast mining can be fully attributed. The process approach to management is the framework of the advanced control of both day-to-day operation and progression. This approach assumes delegation of authority and liabilities through the totality of interacting processes of mining-loading, haulage and unloading, which are considered as a stable (repeated) activity on conversion of 
resources (energy sources, materials, monetary assets) into results (target technical and economic indexes).

Thus, a package of studies is supposed to be carried out on the basis of a systemic approach using the methodology of simulation modeling of the studied mining and haulage processes, providing adequate accounting for the order and sequence of the main technological operations with due regard to specific geotechnical, geometrical, geological, organizational and economic conditions for the functioning of the main technological facilities of opencast mines [6-11].

The algorithm of simulation logical and statistical modeling of mining and haulage processes using motor transport, with appropriate account of fuel consumption versus duties and operation condition of the main process equipment assumes serial and operation-by-operation automated interrogation on the condition and location of machines in an opencast void. Based on the rated traction performance, service life and loading conditions of dump trucks, as well as on the physical and mechanical properties of rocks, quality of road surfacing and speed limits, the algorithm allows realtime estimate of dump truck velocities and fuel consumption. In this manner, during a model shift, the actual fuel consumption is found for load, empty and idle machines. Depending on haulage volume and actual haulage distances, specific fuel consumptions are found for each machine in use. Thus, the adequate account of fuel consumption becomes possible as function of process, technology or management decision application.

It should be noted that the traditional economy, adapted to a functional rather than a process approach in the mining and haulage management, which is currently used at mines, allows incomplete qualitative assessment and optimization of energy efficiency and / or inadequate assessment of energy consumption standards per mining and haulage process. Within the framework of the proposed approach, during simulation modeling and research, the economic and mathematical modeling uses the process approach, which provides an adequate account of the order and sequence of operation-byoperation cost of functioning of the mining and haulage facilities as a whole.

\section{Energy efficiency improvement: trends and approaches}

Based on the specifics of the objects, adopted approaches and research methods, the main routes of the search for the potential to reduce energy consumption and to increase the energy efficiency of mining and haulage operations are determined as: selection of appropriate models, optimization of the modes and conditions of the main mining and haulage equipment operation.

Within the framework of the first route, the technical condition of the main mining and haulage equipment, its workforce and the numerical ratio machines engaged in loading, haulage and unloading are of great importance. In this aspect, it is important to take into account the rated traction characteristics of machines and their main technological parameters - bucket and body capacities, cycle times, engine power, etc.

In accounting and optimization of operating modes of the main mining and haulage equipment, speeds (accepted speed limits), loading modes and data card (pyramid loading, even with body sides), physical parameters of rocks (bulk

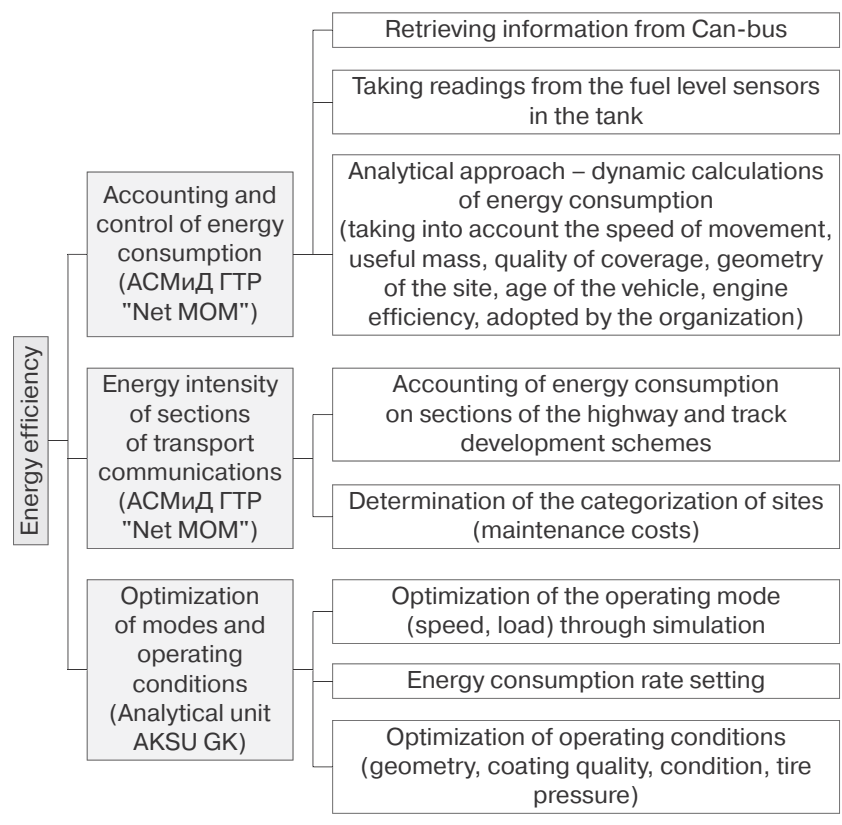

Fig. 1. Concept of energy efficiency in opencast mines.

density and fragmentation degree). The technical condition and operation modes of the machines are interrelated and mutually dependant, which requires adequate consideration of these factors.

To adequately take into account the operating conditions of the main mining and haulage equipment, which significantly determine the total energy consumption, it is important to consider such factors as the surface quality and length of roads, the accepted speed limits, the interaction between mining and haulage equipment, the condition and quality of automobile tires, the structure and geometrics per road sites (slope, distances, length of adjacent sites if any), number and arrangement of loading and unloading points, shift change and equipment examination, etc. As practice shows, it is the speed limits at the points of loading and unloading, at intersections and exits, as well as at various purpose sites that play a significant role in the energy consumption by transport units.

In mining and haulage management, it is critical to reliably take into account the technological interconnection of various mining and haulage machines, as well as the traffic flow crossing or distribution in an opencast.

One of the approaches to energy consumption reduction of truck-and-shovel systems in opencast mines can be the optimization of the location of shipping sheds in the opencast space and points of dump truck shift change since this largely determines kilometrage of the machines per shift.

The potential and approaches to energy efficiency enhancement essentially depend on reliable assessment of specific energy consumption.

\section{Energy Efficiency Improvement Potential Assessment}

In order to assess the potential of the proposed approach to improving energy efficiency of mining and haulage operations in opencast mines, the comprehensive energy audit was carried out for the coal mines of Shubarkol-Komir LLP.

The West and Central opencast mines of Shobarkol-Komir use dump trucks - 9 BelAZ-75306 machines with service life 
to $2010-2017,4$ BelAZ-75307 machines of 2016 manufacture, 5 BelAZ-75131 machines manufactured in 2013-2015, 1 BelAZ-75581 machine manufactured in 2017, 6 BelAZ-75473 machines manufactured in 2010-2012, 4 Hitachi-3500-ACI machines manufactured in 2013-2015, 2 Hitachi EH-1100 manufactured in 2013 and 2017, and 10 CAT 777E machines manufactured in 2018-2019.

The specification data and process variables of the main mining and haulage equipment are assumed according to Shubarkol-Komir's paperwork and from the ratings provide by manufacturers.

Economics includes accurate estimates of salaries of operators and operator assistants of shovels and dump trucks, energy source prices, and extra expenses connected with the main mining and haulage equipment. The costs of the road construction and maintenance were taken from the applied research data on five common types of road surface. The economics is calculated for 7 cold months and 5 warm months with regard to quality and price of diesel fuel.

The aspect of the work organization included the actual operating mode of mining and haulage machine systems in both opencast mines. The total number of working days is assumed as 365 . The company has adopted a two-shift 12-hour work schedule. Each car is serviced by 4 teams of operators and assistants.

In both opencast mines, the 2020 performance is assumed as the main initial technical and economic data. The standard volumes of mining and haulage operations are assumed as follows:

- Central opencast: rock mass - $25432.622 \mathrm{Km}^{3}$; overburden $-19879.014 \mathrm{Km}^{3}$; coal $-5553.608 \mathrm{Km}^{3}$. Here, the bulk density of overburden is taken equal to $2.25 \mathrm{t} / \mathrm{m}^{3}$ and the stripping ratio is 3.27 ;

- West opencast: rock mass - $17004.352 \mathrm{Km}^{3}$; overburden $-12156.424 \mathrm{Km}^{3}$; coal $-4847.929 \mathrm{Km}^{3}$. Here, the bulk density of overburden is taken to be $2.23 \mathrm{t} / \mathrm{m}^{3}$ and the stripping ratio is $2.11 \mathrm{~m}^{3} / \mathrm{t}$.

The models of mining and haulage machine systems in the opencasts are built as of 2020 and include all actual geometrical, geotechnical and geological conditions of their functioning. The structure and procedure for dividing roads into block sections corresponds to the specific technology and geology of the opencasts.

The analysis of workload and energy consumption by block sections of the internal road network in the opencasts allows their ranking with a view to optimizing payout connected with the road surface quality maintenance in the most energyintense sections toward energy and fuel saving.

In the above list of dump trucks, the most energy-saving models are: CAT-777E, BelAZ-75307 and BelAZ-75581 in the Central opencast; CAT-777E in the West opencast.

Regarding the shovel fleet of the Central opencast mine, according to the simulation results, it can be noted that out of 15 machines (three diesel-driven and 12 power-driven), of six models in the list fleet, 12 machines have service life of 30 years or more. About 10 machines are involved in the implementation of the planned annual load. The average shift time use factor is 0.44 . The annual volume of total energy consumption for process needs is at the level of $9983128.15 \mathrm{~kW}$.

For the shovel fleet in the West opencast, including 12 machines ( 2 diesel-driven and 10 power-driven) of four models (Table 2 in Appendix 3), it can be noted that the energy consumption is about $7747859.68 \mathrm{~kW}$ per year. Electricity and diesel costs account for $34.7 \%$ of the total excavation costs which make $5.62 \%$ in the total mining and haulage costs. The vehicle condition is better in this opencast than in the Central opencast mine, but 8 machines also have service life of about 30 years, and 2 machines have been operated for more than 20 years. The average shift time use factor of the shovels is $39 \%$.

The total cost of energy sources in the overall operating costs of mining is $22.47 \%$ in the Central opencast and $18.46 \%$ in the West opencast, including, respectively, 89.43 and $93.28 \%$ of cost connected with dump trucks. However, the processes of loading, haulage and unloading are links in the same technological chain with one product at the outlet, which suggests that the prospects and implementation of the existing energy saving potential at the mines are associated with the challenge of energy efficiency enhancement in mining and haulage within the framework of activities undertaken to increase the economic efficiency of the geotechnological facilities as a whole.

A feature of mining and haulage in both opencast mines is internal dumping, which disables implementation of the existing potential for increasing their energy efficiency. A certain minimum potential for the increase in energy efficiency of mining and haulage operations can be materialized by ensuring the surface quality of the internal roads in the opencasts. This requires comprehensive monitoring of the road loads per sections in both opencasts.

Another feature, though with a certain potential for increasing the energy efficiency of mining and haulage in the opencast mines, particularly in the Central opencast mine, is a wide range of models of dump trucks and shovel which have different rated energy efficiencies and operate in the same geotechnical, geometrical, geological, economic and organizational conditions.

The opencast mines use depreciated mining and haulage equipment is used, which, as manufacturing practice and research show, is associated with the increased energy consumption governed by service life and technical condition of the machines. This is especially true for dump trucks.

The analysis of the initial information provided by opencast mine and characterizing the state and efficiency of mining and haulage operations show that one of the energy efficiency improvement trends can be the better rating of fuel consumption based on the real-time monitoring, age and technical condition of the machines, seasonality of their work, fuel prices per seasons, as well as on the overall economic performance of mining and haulage.

In order to ensure adequate conditions for increasing energy efficiency of geotechnological facilities at opencast mines, it is necessary to continue the purposeful development and improvement of the suitable ecological environment digital data base, analysis and procedures. transition of the management from function-based to process-based control, introduction of economic elements of the process-based control, creation of teams of managers-analysts and adaptation to local scientific and innovative potential challenges.

The energy efficiency increase potential of the mining and haulage facilities of the opencast mines was estimated in two directions: quality improvement of road surface in the most loaded and energy-consuming sections and optimization of the machine fleet structure. 
In the first direction, we considered the options connected with the change the unpaved rolled surface to dry primer coating on the active traffic and most loaded internal roads $9613.12 \mathrm{~m}$ long in the Central opencast and $5957.07 \mathrm{~m}$ long in the West opencast. The total length of the roads with improved surfacing at Shubarkol-Komir will be $15570.19 \mathrm{~m}$, or $36.2 \%$ of the total length of internal roads involved in the current mining and haulage operations. This makes it possible to reduce energy consumption as a whole along the internal roads of the opencasts, respectively, from 2.02 to $1.99 \mathrm{I} / \mathrm{m}$ and from 1.54 to $1.43 \mathrm{l} / \mathrm{m}$. At the same time, the specific fuel consumption in the working fleets of dump trucks in the opencast mines is reduced by 2.68 and $2.3 \%$, respectively, which is accompanied by an increase in the efficiency of the mining and haulage systems and by a decrease in the specific operating costs by $2.11 \%$ and $0.81 \%$, respectively, as follows from Tables 1 and 2.

The implementation of these measures will require extra one-time expenses at the level of KZT 12,5 M for road construction (with depreciation coefficient of 0.3 ) and KZT 4,67 $M$ for annual current maintenance, which in total is: $12.5 \times 0$. $3+4.67=\mathrm{KZT} 8,42 \mathrm{M}$. This will make it possible to obtain an economic effect of KZT 242,132,65 K/year in the Central opencast and KZT 53,580.0 K/year in the West opencast, or KZT 295,7 M/year for the Company as a whole.

The second direction of the energy consumption reduction per opencast is associated with the optimization of the dump truck fleet structure at the same fleet of loading machines, as well as at the same conditions and modes of their operation. In this research area, the various combination options of mining and haulage equipment within the existing fleet are examined.

In these variants, less energy-efficient machines for the given operating conditions are alternately replaced by more efficient dump truck models from the list of dump truck models available in the fleet. In the Central opencast mine, it is proposed to purchase and use stage-wise 4 most efficient dump truck models. At the first stage, two BelAZ-75473 dump trucks and 5 BelAZ-75131 dump trucks were replaced by 3 BelAZ75581 dump trucks and 1 CAT-777E dump truck in the list of vehicles. The former models are manufactured in 2017, and the latter model is manufactured in 2018 . This can be implemented within one year, at the subsequent stages of the renovation adhered to the adopted strategy, which, of course, will lead to a further increase in the overall efficiency and economically feasible energy saving of mining and haulage operations at the mine. As a result, at the same performance, the total specific fuel consumption decreases from $104.69 \mathrm{~g} / \mathrm{tkm}$ to $88.24 \mathrm{~g} / \mathrm{tkm}$, or by $15.71 \%$ in the reference variant and by $13.49 \%$ in the variant with improved road surfacing. In this case, the total cost of mining and haulage decreases from $451,02 \mathrm{KZT} / \mathrm{m}^{3}$ to $411,59 \mathrm{KZT} / \mathrm{m}^{3}$, or by $8.74 \%$, which indicates a general significant increase in the mining and haulage efficiency, including $2.11 \%$ and $6.63 \%$ in the first and second directions, respectively.

For the West opencast, given the most energy efficient dump truck here is CAT-777E, we considered a mining and haulage system composed of the single model machines as a promising option for increasing energy efficiency.

It is assumed that 23 CAT-777E dump trucks have a uniform age distribution with a depreciation period of 7 years, the corresponding depreciated cost and transmission efficiency.
The optimal number of dump trucks to ensure up to $103.05 \%$ of the planned rock excavation in 2020 is 21 machines at the accountable strength of 23 machines. At the same geotechnical, geological, geometrical, economic and organizational conditions, this variant provides a specific fuel consumption of dump trucks as $79.05 \mathrm{~g} / \mathrm{tkm}$, which is less by $21.11 \%$ than the same indicator in the reference variant and by $19.25 \%$ that in the variant with improved road surfacing. At the same time, the unit cost of mining and haulage operations is reduced to $340,07 \mathrm{KZT} / \mathrm{m}^{3}$, or by $12.64 \%$ and by 11.96 as compared with the reference variant and improved road surfacing variant (Table 9). The average dump truck speed rises to $18.41 \mathrm{~km} / \mathrm{h}$, or by $6.57 \%$ and $2.06 \%$ as against the the reference variant and improved road surfacing variant, respectively.

Evaluation of economic efficiency by the variants is carried out within the framework of the process-based management economics approach. The economic efficiency of functioning of a geotechnological system is estimated, and the options of its optimal operation are determined.

This approach to the economic assessment provides an adequate account of the functional causal relationship between subsystems and elements of the mining and haulage facilities, as well as the sensitivity of the mining and haulage process to varying parameters of both each of the subsystems and the entire system. As the main criterion of economic efficiency at the first stage of optimization, the indicator of the current unit costs, formed according to the principles of process-based management economics, is taken [12-14].

The total annual economic effect after implementation of the considered package of measures to improve energy efficiency, including road quality improvement, replacement of less efficient dump trucks by higher energy efficient machines in the given operation conditions, as well as optimization of service lives of the machines in the opencast mines of Shubarkol-Komir may amount to KZT 1839,59 M/year, including KZT $1002,87 \mathrm{M}$ in the Central opencast and KZT 836,72 $\mathrm{M}$ in the West opencast. Regarding total economic effects per opencasts, respectively, KZT 242, 13 and 58,38 M falls at improved road surface; KZT 460,24 and 408, $12 \mathrm{M}$ - at energy-efficient machines; KZT 300,5 and 370,22 M - at optimization of the machine service lives.

\section{Conclusions}

The studies have shown that energy conservation is conventionally one of the key challenges. The regular activities in this respect are usually connected with main mining and transport equipment availability, fuel consumption monitoring and auditing, as well as with energy consumption planning and rating based on the estimated volumes of excavation per planning period. In the meanwhile, the analyses of the available information and the related studies show that the test opencasts have a significant reserve for improving energy efficiency of mining and haulage operations, which requires appropriate methodological support.

References

1. Mineral commodity summaries 2015. U.S. Geological Survey. Virginia, 2015. 196 p. Available at : https: //minerals. usgs.gov/minerals/pubs/mcs/2015/mcs2015.pdf (accessed: 16.04.2021). 
2. Lisenkov A. A., Kuandykov A. A., Bukeikhanova S. S., Lysenko S. B. Intellectualization of systems of design, management and functioning of mining production. Gornaya promyshlennost. 2017. No. 6 (136). pp. 88-91.

3. Voltkovskaya N. S., Semyonov A. S., Fedorov O. V. Energy efficiency and energy saving in the energy saving systems of mining enterprises. Vestnik Gomelskogo gosudarstvennogo tekhnicheskogo universiteta im. P. O. Sukhogo. 2019. No. 3. pp. 52-62.

4. Varichev A. V., Kretov S. I., Ismailov R. I., Badtiev B. P., Vladimirov D. Ya. An integrated approach to intelligent production management systems. Gornaya promyshlennost. 2016. No. 3(127). pp. 4-15.

5. Dindarloo S. R., Siami-Irdemoosa E., Frimpong F. Measuring the effectivity of Mining shovels. Mining Engineering. 2016. Vol. 68, No. 3. pp. 45-50.

6. BauernhansI T. Die Vierte Industrielle Revolution - Der Weg in ein wertschaffendes Produktions paradigm. Industrie 4.0 in Production, Automatisierung und Logistik. 2014. pp. 3-35.

7. Anpilogov A. E., Vagin E. B. Optimization of the transport process at opencast coal mines using simulation and statistical modeling. Scientific and technical conference on quarry transport: Abstracts report. Sverdlovsk, 1978. pp. 32-33.

8. Tkach V. M., Solomakha V. N. Assessment of competitive potential of iron ore mines - a basis of formation of strategy of their development in the conditions of globalization.
Gornyi Zhurnal. 2015. No. 3. pp. 62-65. DOI: 10.17580/ gzh.2015.03.10

9. Sokolovskiy A. V., Cherskikh O. I., Kainov A. I. Strategy and parameters of development for opencast coal mines of SUEK company. Gornyi Zhurnal. 2015. No. 11. pp. 62-65. DOI: 10.17580 / gzh.2015.11.12.

10. Koishina A. I., Kirisenko O. G., Koilybayev B. N., Agayeva K. K. Decision-making for choosing of geological and engineering operation: Current status and prospects. News of the National Academy of sciences of the Republic of Kazakhstan. Series of geology and technical sciences. 2018. No. 4. 2018. pp. $155-167$.

11. BS 1192:2007+A1:2015. Collaborative production of architectural, engineering and construction information - Code of practice. London : BSI Standards Limited, 2015. 39 p.

12. Kaplan A. V. Management of social and economic development of a mining enterprise. Moscow : Economika, 2015. 270 p.

13. Kaplan A. V., Galiev S. Zh. Processor control over opencast mining and transportation machinery based on economic criteria. Gornyi Zhurnal. 2017. No. 6. pp. 28-33. DOI: 10.17580/ gzh.2017.06.05

14. Galiev S. Zh., Galiev D. A., Seitaev E. N., Uteshov E. T. Unified methodology for management of a geotechnological complex in opencast mining. Gornyi Zhurnal. 2019. No. 12. pp. 70-75. DOI: 10.17580/gzh.2019.12.15 